\title{
Allogeneic hematopoietic stem cell transplantation as the first-line treatment option in a patient with severe aplastic anemia without a matched related donor: A case report
}

\author{
SHUN-NENG HSU ${ }^{1}$, JIA-HONG CHEN ${ }^{1}$ and WOEI-YAU KAO ${ }^{1,2}$ \\ ${ }^{1}$ Division of Hematology-Oncology, Department of Medicine, Tri-Service General Hospital, \\ National Defense Medical Center, Taipei 114; ${ }^{2}$ Division of Hematology-Oncology, \\ Department of Medicine, Buddhist Tzu Chi General Hospital, Taipei 231, Taiwan, R.O.C
}

Received January 8, 2013; Accepted June 19, 2014

DOI: $10.3892 / \mathrm{ol} .2014 .2341$

\begin{abstract}
The outcomes of matched unrelated donor (MUD) hematopoietic stem cell transplantation (HSCT) and immunosuppressive therapy (IST) in patients with severe aplastic anemia (SAA) remain controversial. The clinical outcome in patients that undergo transplantation following failed IST is typically poorer when compared with patients that initially underwent transplantation. Clinical treatment algorithms have been proposed to determine the management of such patients, and account for individual conditions, personal preferences and prognostic risk factors. The present study reports the promising outcome of a 22-year-old patient exhibiting SAA. The patient underwent peripheral blood stem cell transplantation (PBSCT) from an MUD using a fludarabine-based conditioning regimen and low-dose total body irradiation as an alternative method to first-line IST. The patient achieved rapid bone marrow reconstitution and has been in complete remission for 32 months. The aim of the fludarabine-based conditioning regimen with PBSCT was to improve the patient's therapeutic outcome and provide a convenient treatment strategy. Furthermore, this regimen extends the application of HSCT to patients who are older or those that are without a matched related donor.
\end{abstract}

\section{Introduction}

Severe aplastic anemia (SAA) is a rare and potentially fatal disease that is characterized by an immune-mediated functional impairment of hematopoietic stem cells and predominantly

Correspondence to: Dr Woei-Yau Kao, Division of Hematology-Oncology, Department of Medicine, Tri-Service General Hospital, National Defense Medical Center, 325, Section 2, Cheng-Kung Road, Neihu, Taipei 231, Taiwan, R.O.C.

E-mail: lemo1900soon@gmail.com

Key words: unrelated donor, peripheral blood transplants, allogeneic hematopoietic stem cell transplantation, aplastic anemia, bone marrow transplants affects young adults (age range, 20-39 years) (1). The treatment of SAA includes immunosuppressive therapy (IST) and hematopoietic stem cell transplantation (HSCT) $(2,3)$. IST with antithymocyte globulin (ATG) and cyclosporine (CsA) is the first-line therapy in children and young adults who are unsuitable candidates for HSCT or without a suitable donor. HSCT, with peripheral blood stem cell transplantation (PBSCT) or bone marrow transplantation (BMT), is the treatment of choice for young patients who have a matched related donor (MRD). A number of previous studies have demonstrated successful HSCTs using a matched unrelated donor (MUD), with outcomes similar to those of patients who underwent MRD HSCT. This treatment option is currently reserved for patients who do not respond to IST, exhibit relapse or develop secondary clonal disorders following IST (4). A recent review demonstrated that an MUD HSCT may initially be considered for the treatment of children without an MRD (5). However, the appropriate definition of the lower age limit for HSCT varies considerably across studies. Investigations into extending the application of HSCT to patients who are older or without an MRD are currently in progress (6). Patient provided written informed consent.

\section{Case report}

On 20th March, 2011, a 22-year-old male presented to the Tri-Service General Hospital (Taipei, Taiwan) with a three-month history of SAA. Laboratory examinations prior to non-myeloablative HSCT showed the following abnormalities: Leukocyte count, $0.3 \times 10^{3} / \mu 1$ (reference range, $4.5-11.0 \times 10^{3} / \mu 1$ ); hemoglobin level, $5.8 \mathrm{~g} / \mathrm{dl}$ (reference range, 12.0-16.0 g/dl); and platelet count, $12 \times 10^{3} / \mu 1$ (reference range, $150-400 \times 10^{3} / \mu 1$ ). Subsequent bone marrow examination revealed hypocellularity ( $<20 \%$ of cellular bone marrow) with $10 \%$ of that, which is typically observed in healthy young adults. An MUD was successfully identified with a human leukocyte antigen (HLA) major antigen match (8/8 loci) for the patient, from the Tzu Chi Stem Cells Center (Hualien, Taiwan). The conditioning regimen comprised fludarabine $\left(30 \mathrm{mg} / \mathrm{m}^{2}\right)$, administered intravenously daily for four days (six to three days prior to the transplantation); cyclophosphamide $\left(300 \mathrm{mg} / \mathrm{m}^{2}\right)$, administered intravenously daily for four days (six to three days prior to the transplantation); 


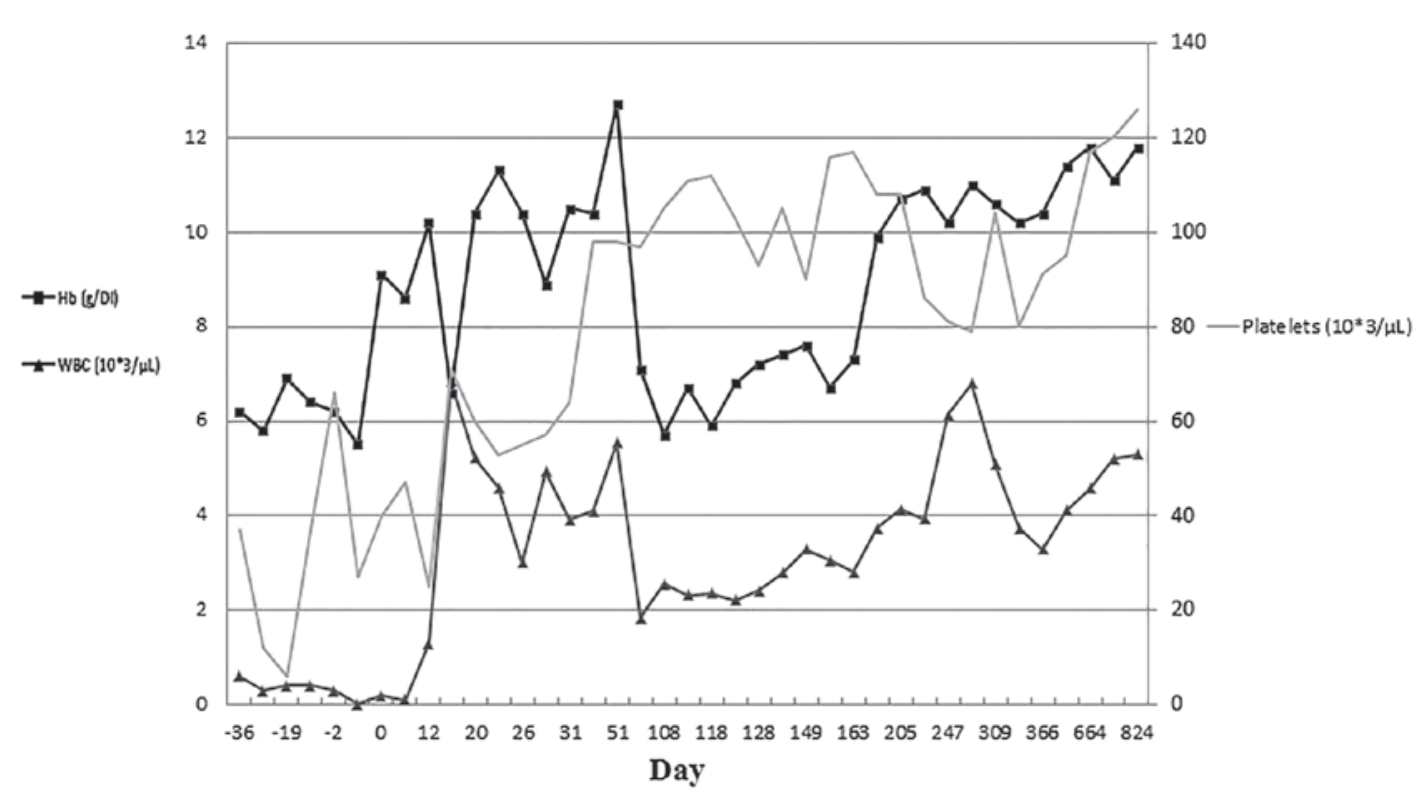

Figure 1. Cell count changes in the peripheral blood following engraftment. Hb, hemoglobin; WBC, white blood cell.

and ATG $(3.75 \mathrm{mg} / \mathrm{kg})$, administered intravenously for three days (five to three days prior to the transplantation) as a 12-h infusion. The patient underwent low-dose total body irradiation (TBI; $200 \mathrm{cGy}$ ) on one day prior to receiving an allograft infusion. The number of cluster of differentiation $34^{+}$cells infused per kilogram of recipient weight was $6.6 \times 10^{6}$ (total, $410.99 \times 10^{6}$ nucleated cells), with a major $\mathrm{ABO}$ blood group mismatch between the recipient (type $\mathrm{O}+$ ) and donor (type $\mathrm{A}+$ ). The patient and the donor tested negative for hepatitis $\mathrm{B}$ and $\mathrm{C}$ viruses, cytomegalovirus and human immunodeficiency virus, as determined by serological tests. Graft-versus-host disease (GVHD) prophylaxis consisted of methotrexate and CsA. Methotrexate was administered intravenously at $10 \mathrm{mg} / \mathrm{m}^{2}$ one day following the transplantation and $8 \mathrm{mg} / \mathrm{m}^{2}$ three and six days following the transplantation. CsA was administered intravenously at $1 \mathrm{mg} / \mathrm{kg}$ as a 12-h infusion on days one, three and six following the transplantation. The dose of CsA was adjusted depending on the presence of a skin rash, as well as liver function. The patient also received filgrastim at a dose of $5 \mu \mathrm{g} / \mathrm{kg} /$ day intravenously, from day one following the transplantation until the white blood cell count exceeded $4 \times 10^{3} / \mu$ l or the neutrophil count exceeded $0.5 \times 10^{3} / \mu 1$ on day 14 following the transplantation. The absolute neutrophil count (ANC) of $1.079 \times 10^{3} / \mu 1$ (reference range, $1.5-8.0 \times 10^{3} / \mu 1$ ) was achieved with a platelet count of $>25 \times 10^{3} / \mu$ l from day 12 following the transplantation for three consecutive days. The donor origin of engraftment was confirmed by polymerase chain reaction analysis of short tandem repeats on day 20 following the transplantation and $>99 \%$ of donor hematopoiesis was recorded in the patient with blood type A. Following successful engraftment 108 days following the transplantation, the hemoglobin level decreased to $5.7 \mathrm{mg} / \mathrm{dl}$, therefore, the CsA dose was adjusted and the ANC and hemoglobin levels gradually increased to within the normal limits without a blood transfusion. The cell count changes of the peripheral blood for the patient are demonstrated in Fig. 1. The preparative regimen was well tolerated and regimen-associated toxicity, including anorexia and enteritis, was mild. No complications involving any infectious diseases occurred in the patient. However, symptoms of acute GVHD were observed on day 10 following the transplantation with a grade I generalized skin rash and abnormal liver function tests, indicating an elevation of aminotransferases. A single dose of methylprednisolone (40 mg) was administered, and subsequently discontinued following the return of normal liver function. However, the sustained engraftment immunosuppressive agent with low dose cyclosporine (50 mg per day) was continued. No recurrence of acute GVHD occurred and to date, chronic GVHD has not been observed. In addition, a good performance status has been observed for $>32$ months.

\section{Discussion}

The treatment of SAA predominantly comprises IST and allogeneic HSCT (2,3,7-9), in which allogeneic HSCT is considered the first-line treatment for young patients with an MRD available, and if the patient is $<40$ years of age $(8,10-13)$. However, $>70 \%$ of patients do not have an MRD $(2,14)$. However, the appropriate definition of the lower age limit for HSCT varies considerably across studies. Clinical treatment algorithms have been proposed to determine the management of such patients, and account for individual conditions, personal preferences and prognostic risk factors (15). Based on these difficulties, the aim of the present study was to extend the application of HSCT to patients who are older or without an MRD.

In previous studies, MUD HSCT has been regarded by the majority of clinicians as the follow-up option for patients who failed to respond to a course of IST $(1,5,14,16)$. Furthermore, various studies have demonstrated that HSCT-associated toxicity may be mitigated by careful selection of patients (e.g. recipient age, time interval between diagnosis and transplantation, and performance status), donors (determined by detailed HLA matching), the conditioning regimen (fludarabine-based regimens) and improved supportive care $(1,5,17)$. Avoidance of IST and multiple transfusions prior to transplantation 
has been reported as a prerequisite for achieving improved survival rates (15). Furthermore, BMT is considered to have a significant advantage over IST with regard to survival rate and the risk of relapse $(4,18)$. The consensus from previous studies is that bone marrow must be used as it is the preferred stem cell source, particularly when a patient is undergoing an MRD HSCT $(19,20)$. When the donor is an MUD, the use of peripheral blood can be proposed as the graft source (21). In Taiwan, HSCT has become the conventional therapy for treating patients with hematological diseases following the initiation of the Buddhist Tzu Chi Marrow Donor Registry in October 1993, using graft types, including peripheral blood (60.4\%) and bone marrow stem cells $(32.0 \%)(22,23)$. In the present case, varying combinations of the conditioning regimen were used, which comprised of fludarabine, low-dose cyclophosphamide and ATG, with low-dose TBI (15). This regimen, in combination with MUD PBSCT, was administered to a carefully selected SAA patient, with the aim of improving the patient outcome using a convenient treatment strategy.

In conclusion, in carefully selected, young patients, it may be appropriate to perform HSCT as the first-line therapy, even when a matched donor is identified, due to the likelihood of greater long-term efficacy and rapid engraftment. The patient described in the present study has been in complete remission with a good performance status for $>32$ months and, therefore, provides a demonstration of the feasibility of this approach. The current study indicates that a PBSCT from an MUD may deliver a promising and curative outcome in young patients without an MRD.

\section{References}

1. Peinemann F, Grouven U, Kröger N, Pittler M, Zschorlich B and Lange S: Unrelated donor stem cell transplantation in acquired severe aplastic anemia: a systematic review. Haematologica 94: 1732-1742, 2009.

2. Brodsky RA and Jones RJ: Aplastic anaemia. Lancet 365: $1647-1656,2005$

3. Young NS, Calado RT and Scheinberg P: Current concepts in the pathophysiology and treatment of aplastic anemia. Blood 108: 2509-2519, 2006.

4. Dezern AE and Brodsky RA: Clinical management of aplastic anemia. Expert Rev Hematol 4: 221-230, 2011.

5. Bacigalupo A and Marsh JC: Unrelated donor search and unrelated donor transplantation in the adult aplastic anaemia patient aged 18-40 years without an HLA-identical sibling and failing immunosuppression. Bone Marrow Transplant 48: 198-200, 2013.

6. Young NS: Current concepts in the pathophysiology and treatment of aplastic anemia. Hematology Am Soc Hematol Educ Program 2013: 76-81, 2013.

7. Bacigalupo A: Guidelines for the treatment of severe aplastic anemia. Working Party on Severe Aplastic Anemia (WPSAA) of the European Group of Bone Marrow Transplantation (EBMT). Haematologica 79: 438-444, 1994.

8. Ljungman P, Urbano-Ispizua A, Cavazzana-Calvo M, Demirer T, Dini G, Einsele H, et al; European Group for Blood and Marrow: Allogeneic and autologous transplantation for haematological diseases, solid tumours and immune disorders: definitions and current practice in Europe. Bone Marrow Transplant 37: 439-449, 2006
9. Marsh JC, Ball SE, Darbyshire P, Gordon-Smith EC, Keidan AJ, Martin A, et al; British Committee for Standards in Haematology: Guidelines for the diagnosis and management of acquired aplastic anaemia. Br J Haematol 123: 782-801, 2003.

10. Marsh J: Making therapeutic decisions in adults with aplastic anemia. Hematology Am Soc Hematol Educ Program 78-85, 2006.

11. Marsh JC, Ball SE, Cavenagh J, Darbyshire P, Dokal I, Gordon-Smith EC, et al; British Committee for Standards in Haematology: Guidelines for the diagnosis and management of aplastic anaemia. Br J Haematol 147: 43-70, 2009.

12. Sugihara T: Treatment guideline for aplastic anemia and the actual status of its applications. Nihon Naika Gakkai Zasshi 97: 1698-1705, 2008 (In Japanese).

13. Ljungman P, Bregni M, Brune M, Cornelissen J, de Witte T, Dini G, et al; European Group for Blood and Marrow Transplantation: Allogeneic and autologous transplantation for haematological diseases, solid tumours and immune disorders: current practice in Europe 2009. Bone Marrow Transplant 45: 219-234, 2010.

14. Horowitz MM: Current status of allogeneic bone marrow transplantation in acquired aplastic anemia. Semin Hematol 37: 30-42, 2000

15. Ades L, Mary JY, Robin M, Ferry C, Porcher R, Esperou H, Ribaud P, Devergie A, Traineau R, Gluckman E and Socié G: Long-term outcome after bone marrow transplantation for severe aplastic anemia. Blood 103: 2490-2497, 2004.

16. Gafter-Gvili A, Ram R, Raanani P and Shpilberg O: Management of aplastic anemia: the role of systematic reviews and meta-analyses. Acta Haematol 125: 47-54, 2011.

17. Stern M, Passweg JR, Locasciulli A, Socié G, Schrezenmeier H, Békássy AN, et al; Aplastic Anemia Working Party of the European Group for Blood and Marrow Transplantation: Influence of donor/recipient sex matching on outcome of allogeneic hematopoietic stem cell transplantation for aplastic anemia. Transplantation 82: 218-226, 2006.

18. Socié G, Henry-Amar M, Bacigalupo A, Hows J, Tichelli A, Ljungman $\mathrm{P}$, et al: Malignant tumors occurring after treatment of aplastic anemia. European Bone Marrow Transplantation-Severe Aplastic Anaemia Working Party. N Engl J Med 329: 1152-1157, 1993.

19. Bacigalupo A, Socié G, Schrezenmeier H, Tichelli A, Locasciulli A, Fuehrer M, et al; Aplastic Anemia Working Party of the European Group for Blood and Marrow Transplantation (WPSAA-EBMT): Bone marrow versus peripheral blood as the stem cell source for sibling transplants in acquired aplastic anemia: survival advantage for bone marrow in all age groups. Haematologica 97: 1142-1148, 2012.

20. Chen J, Lee V, Luo CJ, Chiang AK, Hongeng S, Tan PL, et al: Allogeneic stem cell transplantation for children with acquired severe aplastic anaemia: a retrospective study by the Viva-Asia Blood and Marrow Transplantation Group. Br J Haematol 162: 383-391, 2013.

21. Kojima S, Nakao S, Young N, Bacigalupo A, Gerard G, Hirano N, et al: The Third Consensus Conference on the treatment of aplastic anemia. Int J Hematol 93: 832-837, 2011.

22. Chen PM, Hsiao LT, Tang JL, Yen CC, Liu JH, Lin KH, et al: Haematopoietic stem cell transplantation in Taiwan: past, present, and future. Hong Kong Med J 15: (3 Suppl 3) S13-S16, 2009.

23. Shaw CK, Lin CL, Li CC, Lee TD and Tseng WP: Marrow donor registry and bone marrow transplantation from unrelated donors in Taiwan: initial experience of the Tzu Chi Taiwan Marrow Donor Registry (TCTMDR). Bone Marrow Transplant 23: 727-730, 1999 . 